\title{
La responsabilidad de las Universidades Públicas en México ante los retos del sistema neoliberal
}

\author{
Martha E. Izquierdo Muciño1
}

Sumario: Introducción,-1. La universidad pública en México, -2. Situación actual de país,-3. La responsabilidad pública en México ante los retos del sistema neoliberal,-4. Autogestión y cooperativismo,-5. A manera de conclusión

\section{Introduccion}

La Universidad Publica en México es un factor fundamental para el desarrollo del país, de ella dependerá en gran parte lo que pueda hacerse. Sin embargo observamos que actualmente y ante la inserción de nuestro país al sistema Neoliberal las universidades pasan por una asfixia financiera, que les obliga a replantear sus postulados y a hacer más eficientes sus recursos, ante la amenaza de desaparición de muchas de ellas.

Esta situación obliga a replantear sus valores y sus objetivos, sin embargo no podemos olvidar que desde su inicio (hace casi 100 años), la universidad publica en México ha tenido un gran compromiso con la sociedad y bajo este contexto el nuevo rector de la Universidad Nacional Autónoma de México, Dr. José Narro Robles se ha pronunciado por elevar la calidad académica pero con compromiso social. De hecho todas las Universidades del país coinciden con esta postura y coinciden también al afirmar que los problemas financieros por los que actualmente atraviesan es el resultado de un proceso en el que el estado ha dejando de cumplir sus funciones constitucionales en aras de un proyecto Neoliberal.

1 Doctora en Derecho por la UNAM, Profesor de Carrera por Oposición en la Universidad Autónoma del Estado de México, Pertenece al Sistema Nacional de investigadores (SNI nivel I), con publicaciones en derecho social, derechos humanos y derecho internacional. 
Como consecuencia de dicho proyecto Neoliberal existe gran concentración de riqueza pero por otra parte existe pobreza extrema. Esta situación ha ocasionado desempleo y marginación, economía informal, emigración hacia los Estados Unidos, narcotráfico, crimen organizado, levantamientos sociales, como por ej. el levantamiento del Ejercito Zapatista de liberación Nacional (EZLN) entre otras cosas mas, y nos preguntamos ¿sigue existiendo el compromiso social de las Universidades con la Sociedad? ¿Puede coadyuvar a la solución de los grandes problemas que hoy enfrenta el país? ¿Cuál es el papel primordial de las universidades públicas? ¿Tienen la posibilidad de analizar sobre los efectos devastadores de un sistema que esta por encima de lo social y que lo único que le importa es el dinero?

A fin de poder dar respuesta a todas estas preguntas debemos primero recordar que fue Justo Sierra (Ministro de Educación Publica) quien comprendió que las universidades deberían tener una visión social y Jaime Torres Bidet, gran promotor de la educación y la cultura y representante de México ante UNESCO, quien se pronunció por el compromiso social de las Universidades, para alcanzar la verdad y libertad.

Por tanto reiteramos: ¿la universidad pública debe replantear un nuevo modelo alternativo en el que quepan todos los actores sociales? En donde permee el humanismo y no la desigualdad social ni la exclusión?.

Los estudiantes que son la razón de ser de las Universidades es a quienes toca asumir la responsabilidad de formarse bajo un proyecto innovador, cuyas funciones institucionales destaquen en la cooperación académica, estableciendo relaciones con diversos grupos sociales, mediante el desarrollo de proyectos de investigación y servicios profesionales con fines aplicados, con el objeto de extender los beneficios a la sociedad.

La universidad debe de estar vinculada y comprometida con la comunidad como una institución de servicio, apoyando a la sociedad con programas en donde se incuben empresas sociales, que sean económicas, ecológicas y socialmente sustentables.

En nuestros días la educación es un factor esencial en la conformación de una sociedad libre, justa y democrática, y es a través de la docencia, la investigación la extensión y la divulgación como se puede contribuir a esa gran labor. Por otra parte el proyecto autogestionario y cooperativo parece cobrar nuevo vigor como una alternativa valida para el terreno de la producción económica y de la formación académica, a efecto de contravenir la inercia que los espacios privados y particulares priorizan en su beneficio personal, erra- 
dicando la posibilidad de la cooperación y la autogestión a favor del beneficio colectivo.

Sea por tanto la búsqueda de soluciones viables bajo el apoyo mutuo y las actitudes de solidaridad lo que guié a las universidades públicas de nuestro país a fin de que coadyuve a la solución de sus grandes problemas.

\section{La Universidad Pública en México}

México ha asignado a la educación el papel preponderante de ser una prioridad nacional, traducida en nuestra Carta Magna como el derecho a la educacion (Art. $3^{\circ}$ Constitucional).

Las normas que han regulado a la educación mexicana a lo largo de la historia han tenido como característica el que siempre han expresado los anhelos y las necesidades del país, independientemente del partido ideológico o gobierno que les haya emitido.

Megar Adalid menciona que la historia del país refleja de manera inequívoca la historia de la educación nacional, en tanto que la educación ha sido el espejo de las aspiraciones nacionales y que cada etapa de la historia en la educación nacional está caracterizada por una estructura jurídica bien definida que corresponde a las ideas que sustentaron el periodo correspondiente.

De tal suerte que se destacan 5 etapas principales en el México Independiente.

a. Periodo de la enseñanza libre (1821-1856)

b. Pedagogía de movimiento de la Reforma (1857-1917)

c. La corriente revolucionaria y la educación socialista (1917-1940)

d. La educación al servicio de la unidad nacional (1940-1982)

e. El periodo de la crisis y la necesidad de la modernización educativa (1982-1995) (ADALID, 2004.P.: 63-67)

El artículo $3 .^{\circ}$ Constitucional contiene las bases de la educación de un México el cual lo convierte en todo un programa ideológico que define conceptos como; Democracia, Nación y el sentido de lo social, estableciendo además, criterios que deben orientar a la educación impartida por el Estado, Federación, Estados, Municipios y al Distrito Federal, asiento de los poderes Ejecutivo, Legislativo y Judicial; así como por particulares y por las universidades e instituciones de educación superior autónomas.

Este texto realmente refleja la Filosofía Política que adoptaron los gobiernos emanados de la Revolución Mexicana. (Ídem) 
Actualmente la universidad pública en México resulta ser un factor fundamental para el desarrollo del país, pues en ella se plasman un sin fin de posibilidades tanto económicas como sociales, políticas y culturales.

Gran parte de lo que pueda hacerse dependerá de la formación de los futuros científicos, técnicos, administradores, médicos, etc. capaces de aprovechar los recursos e infraestructura que existe en el país para mejorar o cambiar determinadas formas de organización social.

Desde este punto de vista puede asegurarse que la educación superior juega un papel muy importante en la vida institucional del país, pues de ella dependerán en gran medida sus alcances o sus limitaciones.

La universidad pública por lo tanto debe estar orientada hacia la búsqueda de una sociedad más justa y de un desarrollo mas equitativo, pues en su evolución histórica encontramos que la educación superior siempre desempeñó un papel importante en la construcción del México Posrevolucionario, observando así que las etapas de la educación superior han ido evolucionando de la siguiente manera:

- Educación Superior. Inicia su etapa de crecimiento con el establecimiento de la Universidad Nacional de México en 1910, la cual durante varios años fue la única institución de este nivel.

- Hacia la década 1920-1930 se abren otros centros de educación superior, tales como la Universidad de Yucatán, la Autónoma de San Luis Potosí y Guadalajara.

— En el año de 1929 se da un paso fundamental de otorgarse la autonomía a la Universidad Nacional de México; esta disposición habrá de sufrir diversas modificaciones posteriormente en los años 1933 y 1944.

— En el año de 1935 se crea el Consejo Nacional de Educación Superior y de la Investigación Científica, en dicho consejo se plantean por vez primera los problemas de la educación superior, como el profesionalismo, la centralización, la adecuación al desarrollo, etc.

—En el año de 1937 se creó el Instituto Politécnico Nacional a fin de coordinar la enseñanza técnica, agrupando a todas las escuelas superiores que dependían de la Secretaría de Educación Pública.

- Durante la década 1930-1940 surgen las Universidades de Puebla, Sinaloa y Colima, y las de Nuevo León, Veracruz y Guanajuato en la década de 1940-1950. A partir de 1950 se observa que la educación superior acelera su desarrollo por todo el terri- 
torio nacional, desempeñando un papel fundamental en el desarrollo, político, social y cultural permitiendo un avance que se observa desde la transformación social como es la preservación de la herencia cultural, el avance económico y político etc. Se amplía la oferta de recursos humanos calificados que demanda la sociedad y el propio sistema, para todas las tareas productivas que requiere el país en ese entonces.

- Hacia la década de los 60's una serie de factores externos como las condiciones económicas, sociales y culturales de carácter internacional presionan a los países en vías de desarrollo hacía la búsqueda de un nuevo orden económico internacional y político que haga viable el desarrollo de la humanidad, estos aspectos son:

a. El aceleramiento de la población mundial.

b. Los escasos recursos.

c. El desarrollo de nuevas fuerzas productivas.

d. El desarrollo de las ciencias sociales y nuevas técnicas para el manejo de la acción social.

e. La participación de la juventud y su acelerado crecimiento.

f. El acelerado crecimiento de las empresas trasnacionales a nivel mundial.

g. Contaminación atmosférica entre otras cosas más.

- En la década de los 80's fue publicada en el Diario Oficial de la Federación ( $D$ O F) el 19 de Junio del mismo año, la Reforma al Artículo $3 .^{\circ}$ Constitucional por lo que se garantiza la autonomía Universitaria a la Universidad Pública, dado que dicha autonomía solo había estado reconocida para ciertas instituciones. (MORALES; 81: 21-31)

- En las últimas dos décadas 1990-2000 se observa la adopción de un nuevo sistema en el orden económico como es el sistema neoliberal, y ante la crisis que esto ha traído consigo se obliga a las universidades públicas del país al replantear su estrategia económica, buscando hacer más eficientes los recursos de que disponen ante la amenaza de la desaparición de muchas de ellas, al igual que sucede en varias universidades de los países en Latinoamérica, pues en el marco de la globalización y del neoliberalismo existe una enorme concentración de riqueza, pero por otra parte la extrema pobreza.

En efecto, Karina Avilés en un interesante artículo menciona que varios rectores de importantes Universidades latinoamericanas, expre- 
san un repudio al sistema neoliberal en las Instituciones de Educación Superior Públicas, sosteniendo que el neoliberalismo es «la peor cosa que les ha pasado», toda vez que los conduce a la «agonía» del sistema público universitario por asfixia financiera a la vez que fomenta que los estudiantes le den mayor valor a las conquistas individuales que a las sociales, cita entre otros al rector de la Universidad de Córdova, Argentina, Jorge H. González, quien menciona que después de 10 años de una vida «irreal» el sistema mostró su fracaso, pues se incrementó la pobreza, la marginación, desocupación, destrucción del aparato productivo y fomentó la caída de las economías regionales. (AVILÉS 2003, p. 1-6),

Esta situación impactó fuertemente en las Universidades Públicas a pesar del esplendor con el que el País aparentemente se desenvolvía.

Por su parte en la Universidad de El Salvador, fundada en 1841, su rectora María Isabel Rodríguez, sostiene que nunca en su historia la universidad había recibido un golpe financiero que la hubiese puesto en tanto peligro, pues en las últimas décadas de gobiernos neoliberales su presupuesto cayó $250 \%$ pese a que atiende al $30 \%$ de la población universitaria.

Afirma dicha rectora que «la universidad pública tiene la responsabilidad de analizar y concientizar sobre los efectos devastadores de un sistema que está por encima de lo social y que lo único que le importa es el dinero». (AVILÉS. Ídem)

Pietro Novellino, rector de la Universidad de Río de Janeiro, Brasil. Explica que el sistema es un desastre porque empobreció a la población a costa de privilegiar el área económica y el intercambio monetario entre los países. En Brasil, sostiene, ese modelo ha debilitado el trabajo de las Universidades Públicas porque impulsa intereses propios de la educación superior y fomenta una política elitista, dejándo de lado áreas que en su esquema no sirven y sobre todo porque deja a las instituciones educativas cada vez con menos recursos.

Así mismo, menciona que lo peor de todo es que fomenta el surgimiento del individualismo en los estudiantes, quienes ahora dan más valor a sus conquistas individuales que a las sociales.

El rector de la Universidad Nacional de Colombia (UNC) Víctor Manuel Moncayo Cruz, considera al neoliberalismo no como un simple modelo económico y social, sino como todo un concepto que describe la realidad de una nueva época de organización socio-productiva como lo es el capitalismo, que ha transformado todas las relaciones sociales incluyendo las instituciones educativas, toda vez que la «regla de oro mercantil» del sistema neoliberal desprecia la especificidad de la Universidad Pública a la que ve como una más entre las muchas del sistema. 
Moncayo advierte que el neoliberalismo no comparte la idea de la autonomía universitaria pues la estima opuesta a las necesidades de eficiencia, y busca que las universidades simplemente sean captoras de recursos para garantizar resultados cuantificables requeridos por el mercado.

En la ciudad de Heredia, Costa Rica, está la sede de la Universidad Nacional, Institución Autónoma cuyos fines primordiales son: "contribuir al fortalecimiento de la Identidad nacional y al desarrollo de una cultura propia al servicio de la paz y de la libertad». La rectora Sonia Martha Mora Escalante, opina que las nuevas ofertas están delineadas para las universidades privadas, esto es, delineadas para el desarrollo del mercado, pero no se comprometen con las tareas de investigación y la extensión social, en consecuencia en Costa Rica existe un panorama desafiante para las universidades publicas, quienes deben incrementar la calidad. Su compromiso con la extensión, la investigación y ampliar al máximo la cobertura sin afectar el alto nivel de los estudios que ofrecen.

La universidad de San Carlos en Guatemala, fundada en 1676, tiene una historia de resistencia al igual que la de El salvador, pues en ellas los hechos demuestran que el Estado ha empleado la fuerza terrorista en contra de la Universidad en forma masiva, atacando cualquier forma de aparición aún pacífica. En ella el rector Luís Alfonso Leal Monterroso establece que el efecto del neoliberalismo ha sido tal que hemos acelerado el proceso de reforma universitaria para hacer de nuestros egresados, profesionales capaces de competir con otros que han ingresado a nuestro país con la apertura de fronteras, sin embargo opina que los programas de estudio aún deben perfeccionarse para responder al desarrollo científico, entre otros.

El rector de la Universidad de Zulia, Venezuela, Domingo Bracho, opina que conforme esta teoría económica de educación se ve afectada por la restricción de las fuentes presupuestarias soporte de la academia, teniendo que transferirse la búsqueda de recursos a las matrículas cuyos costos se van haciendo poco accesibles a los grupos sociales de bajos niveles económicos, no permitiendo el acceso a gruesos sectores de la población y asegura que cualquier plan de estudios sujeto a restricciones financieras sufre un impacto que necesariamente disminuye la calidad de la educación.

En Argentina, las universidades públicas se encuentran en una profunda crisis. El rector de la Universidad Nacional de la Plata, Alberto Ricardo Diggern menciona que esta crisis es el resultado de un proceso en el que el Estado incumplió con sus obligaciones constitucionales y dejó de financiar a la educación superior pública con permanentes re- 
cortes presupuestales. Dicha Universidad se negó a cambiar los planes de estudio, la comunidad académica luchó y rechazó las posibilidades de adecuarlos a los designios del mercado. (AVILÉS 2003, p. 1-6),

Por su parte la comunidad universitaria en Chile atraviesa actualmente por una difícil situación, con protestas callejeras y repudio a los cambios en sus planes de estudio que se pretenden adecuar en aras del libre mercado.

De hecho, todos los rectores citados, coinciden al considerar que la Universidad Pública tiene la responsabilidad de analizar y concientizar sobre los efectos devastadores de un sistema que está por encima de lo social y que lo único que le importa es el dinero, modelo al que los distintos gobiernos están sometidos.

Consideran que es necesario replantear las economías de sus países hacia un nuevo orden internacional en el que prevalezca el interés social sobre el individual. Asimismo, coinciden en afirmar que todas las universidades latinoamericanas sufren las severas limitaciones en la provisión de recursos públicos para su funcionamiento y desarrollo, pues como puede observarse, actualmente la Universidad Pública está abandonada a su suerte, sin ninguna responsabilidad por parte del Estado, toda vez que el actual sistema neoliberal minimiza el papel de la Universidad Pública.

Sostienen que éste sistema no crea una conciencia académica, por el contrario la altera, la inmoviliza, la privatiza, la compra, la explota pero no la conduce como patrimonio social, ni cultural ni universitario y lentamente los investigadores y académicos van convirtiéndose en empleados del sistema

En noviembre de 2003 el gobierno federal mexicano, propuso como parte de su ejercicio presupuestal para 2004, la desincorporación, liquidación, extinción o fusión de 17 organismos públicos aduciendo escasez de recursos. Entre ellos se encontraban: el Colegio de Postgraduados de la universidad de Chapingo, El Instituto Nacional de Investigaciones Forestales, Agrícolas y pecuarias, El Instituto Nacional para el Desarrollo de Capacidades del Sector Rural, La Comisión Nacional de Zonas Áridas, El Instituto Mexicano de Tecnología del Agua,, La Exportadora de Sal etc. etc. sin embargo y a juicio de Montemayor, cada uno de éstos organismos mas que representar una carga presupuestal excesiva para el gobierno mexicano, constituían un obstáculo para el negocio de las transnacionales vinculadas con la producción alimentaria, el control de suelo, de recursos forestales, de mantos acuíferos, del comercio de sal etc. (MONTEMAYOR, 2006: p. 1-11)

Además dejar al país sin recursos humanos de alto nivel en estas áreas tan esenciales para la vida productiva del país significa ceder for- 
malmente al «conocimiento técnico» de los consorcios transnacionales y renunciar a la transmisión, producción y ampliación del conocimiento, equivale a la renuncia a los beneficios de la educación y el conocimiento mismo. Por otra parte no hay «mercado» que justifique el desmantelamiento de los Estados ni que obligue a los pueblos a aceptar que la educación y el conocimiento se cancelen y se reduzcan sólo a un acto comercial, ni hay razón comercial que justifique la cancelación de la responsabilidad del Estado con la educación en beneficio de sus propias sociedades, pues renunciar a ello significa retroceso, mas nunca el progreso de la especie humana (Idem)

\section{Situación actual del país}

no obstante los derechos sociales sobre la educación en México (artículo $3 .^{\circ}$. Constitucional), garantizados por el Estado mexicano, a partir de nuestra inclusión en el libre mercado mediante el Tratado del Libre Comercio de las Américas, en adelante TLCAN, se observan los efectos negativo en nuestro país, pues existe un grave aumento del desempleo que provoca salarios cada vez más bajos, carencias de seguridad social, e inestabilidad laboral y de derechos sociales que con tanto esfuerzo se habían logrado establecer y aún cuando las economías se reactivan y los volúmenes de negocios aumentan, esto no se refleja ni en la cantidad ni en la calidad de los empleos generados y menos aún en la disminución de la pobreza.

Alicia Puyana y José Romero, en un interesante artículo que realizan, sostienen que con la apertura de nuestro país al comercio internacional mediante el TLCAN, se esperaba la transformación de las funciones de producción y con ello elevar de manera sostenida la productividad, asimismo se esperaba revertir la pérdida de competitividad en los mercados internacionales, recuperar su participación en el intercambio global, avanzar en la industrialización con mayor productividad, reducir el desempleo y el subempleo, incrementar los ingresos al separar la ineficiente asignación de factores productivos y elevar la formación de capital fijo, al establecer un ambiente propicio para las inversiones extranjeras y nacionales, mediante la disciplina fiscal, (PUYANA, 2007, : 796-812)

Sin embargo según manifiesta, la realidad es que a 14 años de la entrada en vigor del TLCAN y bajo la promesa de que con dicho convenio se revertiría la pérdida de competitividad de los mercados internacionales, recuperando la participación en el intercambio global, avanzando en la industrialización con mayor productividad, reduciendo el 
empleo y el subempleo etc. lo que se observa en la actualidad es una creciente insatisfacción con la trayectoria de la economía mexicana, pues la economía se abrió y el Estado se transformó, pero no se vislumbra aún ni mayor productividad ni avance de los sectores del Producto Interno Bruto.

Lo más preocupante es la evidente disociación entre el crecimiento de las exportaciones y el empleo de las manufacturas que conforman el $85 \%$ de las ventas externas mexicanas.

El déficit comercial agroalimentario crece y el país depende cada vez mas de las importaciones para satisfacer su demanda de alimentos y la agricultura; ante estas circunstancias se engrosa la informalidad urbana o se intensifica la emigración hacia Estados Unidos.

Por otra parte sostienen que en los últimos 20 años, fue muy acelerado el incremento de la población que buscó trabajo, pues en 2005 la fuerza de trabajo como porcentaje de la población total fue de $41.5 \%$, mientras que en 1970 fue apenas de 26.9\%. En 2005 superó en 5.7 porcentuales la de 1983. Menciona que la participación masculina asciende a $80 \%$ y la femenina a $60 \%$, lo que indica una amplia reserva laboral femenina por incorporarse al mercado de trabajo, ya que sólo el $47 \%$ de la población femenina en edad de trabajar participa en la población económicamente activa (PEA).

Sin embargo la falta de seguridad social y de ahorros personales, obliga a la población en edad de retiro a mantenerse activa sobre todo a las mujeres, en condiciones laborales difíciles, por la competencia de los jóvenes, mas educados y entrenados en las nuevas tecnologías, estas desventajas empeoran para las mujeres que buscan empleo por primera vez, lo cual se corrobora por el hecho de que se dedican más a actividades de baja productividad y al servicio doméstico. (PUYANA, 2007: 802)

Félix Cadena por su parte (CADENA, 2005: 14-16) realiza una síntesis de algunos datos que caracterizan la actual situación en México, basado en diferentes y confiables fuentes de información como a continuación se menciona:

1. El empleo nos dice Félix Cadena, en el sector manufacturero de diciembre del 2000 a junio del 2005, pasó de 17,181,000 a $14,270,000$ empleos, lo que muestra una pérdida de casi tres millones. En el mismo lapso en México, en el mismo sector, se pasó de 4.383,000 de empleos a 3, 890,000 es decir casi 500 mil menos. (Fuente: STPS y Buró de Estadísticas laborales de EU).

2 En el conjunto de la actividad económica, el crecimiento arrojó los siguientes datos: El mayor aumento del PIB de los últimos 
cinco años, se dio en el 2004, en que llegó al 4.4. Sin embargo en ese año, el número total de personas ocupadas en todo tipo de actividades creció en 642 mil, respecto del 2003, en tanto que la PEA en ese mismo año, aumentó en 741 mil personas, lo que significa que el saldo de cualquiera manera fue negativo ya que cien mil mexicanos pasaron a engrosarlos millones de desempleados y subempleados ya existentes. (Encuesta Nacional de Empleo $4 .^{\circ}$ trimestre del 2004).

3. Según datos del Instituto Mexicano del Seguro Social (IMSS), de enero 2001 a enero 2005 se crearon sólo 56 mil 300 nuevos puestos de trabajo, lo cual significa una tasa media del 0.1 , que resulta a todas luces insuficiente, si se observa desde el punto de vista práctico, (Educación, Productividad y Empleo No. 85 marzo 2005).

4. En el año 2000, de acuerdo con el informe de competitividad 2004-2005 del Foro Económico Mundial, México ocupaba el lugar \# 43, cuatro años después está en el 48, lo que está correlacionado con el hecho de que en calidad del sistema educativo ocupábamos también en el 2000 el lugar 50, pasando cinco años después al 77, En calidad de servicios de salud, se ocupaba hace cuatro años el 47 y en 2004 se pasó al 89. En eficiencia del gobierno para reducir la pobreza y la desigualdad, aparecemos en el sitio 75.

5. En cuanto a este último aspecto, México tiene uno de los mayores índices de inequidad en la distribución del ingreso. Según la encuesta ingreso-gasto del INEGI 2004, el $10 \%$ de la población mas rica recibió el $42.1 \%$ de los ingresos, creciendo a una tasa del 3.4 por ciento entre 2002 y 2004, mientras que en el mismo periodo el porcentaje del $10 \%$ de los más pobres sólo creció al $1.5 \%$, lo que hace que la distancia entre el ingreso de los hogares más pobres y del promedio de los más ricos sea de más de 30 veces y está en constante aumento.

6. La mano de obra mexicana en el sector formal, es de las más baratas del mundo!, debido a que perdió más del $70 \%$ de su poder adquisitivo en los últimos 37 años Actualmente se cotiza en promedio a 2.4 USA dlls., la hora, por debajo de Brasil 2.6, Hong Kong 5.5 y Taiwán 5.8, según estudio de la Universidad Obrera dé México (el Financiero 20. 06. 2005).

7. Por otra parte, la productividad del trabajador mexicano va en constante aumento: en el comercio fue de $7.9 \%$, en la maquila del $2.7 \%$, en la manufactura del $6.3 \%$, con un ritmo durante los años del 2000 al 2004, de 32.5.\% anual. Sin embargo en el 
mismo lapso, la plantilla de trabajadores de este sector se redujo $14.5 \%$, equivalente a casi 220 mil plazas (Educación Productiva y Empleo. No. 87. mayo del 2005)

En base a los datos citados, sostiene que México a pesar de ser la décimo segunda economía, según el BM, en lo que se refiere al Índice de Desarrollo Humano elaborado por el PNUD, está en el lugar 53 y aunque mejoró un punto respecto de 2003, debido en gran medida a los cientos de miles de buscadores de empleo que emigran y a los más de 17 mil millones de dólares en remesas recibidas por sus familiares ese año, lo cierto es que estamos por debajo de Croacia, Letonia, Islas Bahamas, Chile y Cuba. Incluso algunos municipios del país se encuentran en situación equivalente a Tanzania y Malawi, que ocupan los lugares 162 y 165 respectivamente (PNUD índice de Desarrollo Humano 2004).

Los datos mas recientes sobre el empleo y bajo el primer año del presidente Felipe Calderon «el presidente del empleo», como el mismo se hizo llamar, revelan que las cosas no marchan mejor. (REVISTA proceso N. ${ }^{\circ}$ 1622. 2 de dic. 2007), además que existe la amenaza generalizada de una recesión mundial como consecuencia de una recesión de los Estados Unidos, toda vez que es la principal economía del planeta.

De hecho al hablar sobre el empleo la reconocida escritora Viviane Forrester, sostiene que lo más funesto no es la ausencia de empleos sino las condiciones de vida indignas, que el rechazo o el oprobio infringidos a quienes lo padecen y la angustia de la mayoría que bajo la amenaza de caer en el desempleo se ve sometida a una opresión creciente.

Menciona esta distinguida autora que la obsesión del empleo crece en la medida de que desaparecen los puestos de trabajo, que es como una lucha interminable puesto que la lucha contra la desocupación provoca que las personas se conformen con magras asignaciones siempre en peligro de disminuir, teniendo por toda perspectiva el «fin de los derechos» como una expresión alucinante de inhumanidad (FORRESTER, 2000: p. 82)

Se pregunta si es posible dar prioridad a los millones de desocupados'? y ella mima responde: imposible! Toda vez que eso sería a juicio de los pocos dueños del trabajo que quedan como dar muestras de un pesimismo imperdonable, un insulto a la promesa del regreso del empleo, promesas solo promesas de recuperar con ello incluso la dignidad, pero el caso es, nos dice, que las empresas al no tener "pudores», son quienes deben ser «socorridas» por medio de excensiones impositivas y subvenciones que aparentemente no les provocan la menor humillación, sosteniendo que no importa que esas empresas subvencionadas tomen personal o se guarden el dinero, pues son tan generosas 
que pudiendo contratar prefieren despedir a muchos. Que si bien se tenía la impresión de que el trabajo era un derecho, la realidad refleja que no era sino sólo una simple impresión. (FORRESTER, 2000: .43)

Adicionalmente, las escasas ventajas obtenidas por unas cuantas empresas exportadoras, con altos costo para la mayoría de los trabajadores y empresarios por la inequitativa y mal instrumentada apertura de mercados basada en el TLC, se están perdiendo frente a la competencia de las economías emergentes asiáticas. En particular el impacto de la competencia de China es crítico.

Sin embargo la economía actual a escala mundial esta creciendo a una tasa de 3\% a 4\% anual en regiones como la del Sahara, en que a pesar de todas las dificultades esta creciendo a $4 \%$ anual, India también esta creciendo a de $7 \%$ a $8 \%$, China a $8 \%$ anual, pero si bien existe un gran crecimiento global, esto es un gran desplazamiento de la riqueza hacia regiones asiáticas, por otra parte existe también concentración de la riqueza. (ATALLI, 2000: 53)

En efecto el crecimiento mundial actual esta sujeto a muchos cuestionamientos como es: la concentración de la riqueza, el aceleramiento de la concentración de la información, de los recursos financieros, de los mercados financieros y de las empresas en beneficio de algunos, lo que significa a corto plazo un gran desequilibrio.

Si bien la globalización ha provocado que el mundo sea un mercado gigantesco, también ha provocado con ello una gran concentración del capital y con ello mucha desigualdad a grado tal que hoy en día el producto de la riqueza de todo el planeta es del orden de cuarenta trillones de dólares por año, de los cuales mas de la mitad es generado por menos del $15 \%$ de la población del planeta y por otro lado dos mil millones de habitantes viven con menos de dos dólares diarios (idem).

\section{Respuestas de la población mexicana}

El citado Félix Cadena considera que las políticas neoliberales y sus efectos excluyentes, han obligado a dar respuestas espontáneas a la propia población afectada, personas que han debido generar mecanismos para resolver los problemas de empleo e ingreso, como a continuación se menciona:

\section{MigRACIÓN}

En primer lugar menciona este autor que por su magnitud e impacto se encuentra la migración. En el caso México, millones de mexi- 
canos han migrado, sobre todo a EE.UU. de manera temporal o definitiva, documentada o indocumentada, aún a costa de su vida. El número de mexicanos que migra cada año se estima en 600 mil y los que mueren cada año intentando cruzar subrepticiamente la frontera norte, es superior a todos los alemanes que murieron durante la Guerra Fría intentando cruzar el Muro de Berlín. Tan sólo de enero a agosto del 2005 se registraron 384 decesos, que superan ya los 373 de todo el año 2004. Por otro lado, las remesas que ellos envían, que para 2004 se estimaron en casi 17 mil millones de dólares constituyen, después del petróleo, la principal fuente legal de divisas para el país y de subsistencia para los millones de familiares que se quedaron en el territorio nacional. Las implicaciones de esto, son de la mayor importancia, pues las remesas y los altos ingresos petroleros actuales, son base de la precaria estabilidad de la economía nacional.

\section{ECONOMÍA INFORMAL}

Bajo el ambiguo concepto economía informal, millones de personas obtienen algún ingreso, desempeñando una gama muy amplia de actividades. Algunas suponen cierto nivel de agregación de valor y otras francamente parasitarias o de piratería. El informalismo responde no sólo a la falta de oferta cuantitativa de empleo, sino también a las bajas remuneraciones que ofrece la mayoría de las empresas del sector formal. En el caso de México, más del $60 \%$ de quienes tiene un empleo formal no recibe diariamente ni siquiera tres salarios mínimos, en tanto que se calcula que una familia requiere, para tener acceso a una canasta básica de bienes y servicios, de por lo menos cinco salarios mínimos. A pesar de las complicaciones inherentes a la cuantificación de la población ubicada en este sector, se estima que se trata de casi el $40 \%$ de la Población Económicamente Activa (PEA). Resulta importante reconocer que frente a la visión negativa que se propaga de este tipo de economía, sobre todo en los medios masivos, sin estas iniciativas que recogen prácticas y estrategias populares de resistencia, y de cooperación, la crisis por la exclusión laboral sería de proporciones inmanejables, al menos desde hace varios años. Por otra parte, asignar a las empresas del sector formal el atributo de ser legales, contrasta con las crecientes noticias sobre prácticas de defraudación que muchas llevan a cabo, no sólo al fisco, sino incluso a sus mismos accionistas y, por supuesto, al consumidor. (CADENA, 2005: 32)

De tal suerte que podemos asegurar según datos recientes, que desde la creación del Instituto Mexicano del Seguro Social (IMSS), en 1944, el empleo formal fue el segmento mas dinámico del mercado la- 
boral, posteriormente en 1989 llegó a representar el 38.7\% del empleo total. Después de ese año la participación del empleo formal decreció hasta alcanzar un nivel mínimo de $24.5 \%$ en 1996 . Se recuperó ligeramente a principios del 2000 concentrando 30.2\% de la ocupación total. (PUYANA, 2007: 804).

Lo anterior significa que de 1989 a 2005 más del 70\% de la fuerza laboral, debió buscar trabajo en el sector informal. Y en números absolutos puede afirmarse que el número de personas vinculadas al sector informal en 2005 fue casi dos veces mayor que en 1989, al punto de que en 2004, de los 26.5 millones de trabajadores asalariados registrados en la encuesta de ingresos y gastos de empleo, 14 millones contaban con algún tipo de seguridad social y 12.5 millones carecían de ésta. Ahora bien si se considera que el $9 \%$ del total de trabajadores no percibe renumeración alguna, es probable que el empleo precario sea mucho mayor y supere el número de los que gozan de salario y seguridad social.

\section{EL LEVANTAMIENTO DEL EZLN}

Desde la esfera de la política, el levantamiento del EZLN, responde, de acuerdo con sus proclamas a una visión anticipatoria en cuanto a cómo el TLC agravaría la situación de subordinación histórico-estructural que han padecido los habitantes del agro, particularmente las etnias indígenas. En Chiapas, el 1. ${ }^{\circ}$ de enero de 1994, varias de estas comunidades, con el apoyo de activistas sociales egresados de universidades como el Subcomandante Marcos, realizaron este levantamiento poniendo en juego tácticas que conjugaban el icono de la guerrilla, con la capacidad de utilización estratégica de los medios masivos de comunicación, particularmente del Internet, En estos años han formulado iniciativas que se ubican no solamente en; la dimensión de resistencia, sino que representan modalidades de carácter emancipador, al impulsar alternativas para procesos de desarrollo local y micro regional. Sin embargo, esas experiencias, ajuicio de ellos mismos, han llegado a límites que sólo se pueden superar retomando iniciativas de transformación política y social a nivel nacional. Por ello en su reciente Sexta Declaración de la Selva Lacandona anuncian y convocan a esa movilización (2005). El impacto que sus acciones y escritos ha tenido en gran parte del mundo, hace evidente lo pertinente de sus cuestionamientos y de sus propuestas.

\section{CRIMEN ORGANIZADO Y NARCOTRÁFICO}

El incremento del crimen organizado y el narcotráfico constituye otra fase vinculada con la vigencia de valores individualistas. No se 
puede afirmar que sea por la pobreza por lo que una parte creciente de la población se involucra en este tipo de actividades ilícitas. La explicación principal se puede encontrar en el clima de deterioro ético que campea, sobretodo entre las élites políticas y financieras. Con sus actos ilegítimos y abusivos mandan un mensaje a la sociedad de que el crimen paga y que la impunidad se logra con astucia y cinismo.

\section{EL MICRO CRÉDITO}

La promoción del microcrédito como alternativa, por parte de las instancias encargadas de la promoción del empleo en México ha proliferado notablemente. Por un lado, y con base en la experiencia del Graneen Bank, se han impulsado programas de micro crédito, teniendo como hipótesis que lo que hace falta a la población es un poco de dinero para poner un changarro y así obtener algún tipo de ingreso. Otra perspectivas más elaboradas son las de Hernando de Soto, que desde su libro El otro Sendero (1988) y actualmente con El misterio del Capital (2001), llega a la tesis de que los pobres tienen riqueza, pero ésta no se vuelve capital y, consecuentemente factor de producción, en gran medida por falta de visión y, sobre todo, por el obstáculo que representa el hecho de que su propiedad no esté debidamente registrada, sobre todo por las prácticas burocratizadas y muchas veces corruptas que se requiere para lograrlo.

\section{APOYO A PYMES}

A pesar de su importancia, ya que representan más del $95 \%$ de las empresas y generan al $72 \%$ del empleo, es hasta los últimos años a partir del 2002, y con un retraso de más de 15 años al respecto de otros países de la región Latinoamericana que en México se están instrumentando una serie de programas en apoyo a las micro, pequeñas y medianas empresas.

El gran número de servicios y apoyos que a través de 134 programas operando por 12 Instituciones del gobierno Federal, todavía no logra ser bien conocido ni aprovechado por sus destinatarios, agudizado por la insuficiencia de mecanismos que favorezcan la articulación de esos apoyos. La consecuencia es el alto número de estas empresas que fracasan.

En cualquier caso, a pesar de que de 2001 a 2005 la Subsecretaría para pequeña y mediana empresa duplicó los recursos para esas unidades, pasando de 880 millones a 1,532.5, esto no representa ni el 10\% del monto de las remesas que enviaron en el 2004 los emigrantes ra- 
dicados en EUA. El número de empresas que recibieron algún apoyo fue de 343,555.0, lo que no representa más del 15\% de las existentes. (CADENA, 2005: 22 a 24)

Ahora bien, para atemperar los efectos deprecatorios del modelo neoliberal y del consecuente recetario plasmado en el "Consenso de Washington», los últimos tres gobiernos federales, con recursos del Banco Mundial y otras agencias intergubernamentales, se han realizado amplios programas que tienen la función de una ambulancia que recoge las víctimas de la actividad económica.

La trayectoria de la economía mexicana y sus múltiples consecuencias en materia social desde la entrada en vigor del TLCAN hasta nuestros días, sugiere que las metas a lograr como el mayor crecimiento, mejores empleos, mejores ingresos para la población etc. es una tarea aún pendiente, pues lejos de ello lo que se observa es que el país depende cada vez más de las importaciones para satisfacer su demanda de alimentos y la agricultura al perder a los agricultores se incrementa la informalidad urbana ó la emigración hacia los Estados Unidos, esta tarea es tanto asistencialista como preventiva de inconformidades mayores que podrían agudizar el clima de frustración y de descontento social y no obstante que contamos con diversos artículos constitucionales que garantizan un mejor modelo de vida para los mexicanos lo hasta aquí expuesto expresa una realidad diferente.

\section{Responsabilidad de la Universidad Pública en México ante los retos del sistema neoliberal}

algo que no podemos soslayar es la función social de la Universidad Pública, pues en ella se conjugan la verdad y la libertad; la libertad para proseguir en búsqueda de la eterna verdad y la verdad es la afirmación de la responsabilidad social, moral e intelectual que impone la libertad. (Jaime Torres Bodet, citado por: DELGADO, 2007. p. 1 a 3).

Delgado Moya menciona que por los años sesenta se vivía un proceso de expansión y demanda de la educación superior, sin que por ello se olvidara el compromiso social de las universidades del país, y cita a dos grandes ilustres de la educación en México como fueron: Justo Sierra y Jaime Torres Bodet, ${ }^{2}$ y el primero sostenía que: la universidad no debería ser un templo en donde se adorara a Atenea sin ojos para la

\footnotetext{
2 Discurso de la 3ra. Reunión de la Asociación Internacional de Universidades, México 1960.
} 
humanidad y sin corazón para el pueblo, pues en ese contexto la educación superior conduciría a los educandos a una tecnocracia descarnada. ${ }^{3}$ Por su parte Jaime Torres Bodet sostenía que: la misión suprema de las universidades no sólo era la de crear un conjunto de facultades y laboratorios a los que asistieran considerable número de beneficiarios, sino la de construir un centro de verdad orgánico de pensamiento y acción para la transmisión y el renuevo de la cultura, además, que lo que verdaderamente daba al poderío material verdadero significado era la aptitud de emplearlo para el bien de la humanidad.

En un mensaje pronunciado en 1960 afirmó que el pensamiento de Justo Sierra expresado en 1910 aún tenía vigencia, y a casi cien años de distancia, el nuevo rector de la Universidad Nacional Autónoma de México, Dr. José Narro Robles se ha pronunciado por elevar la calidad académica pero con compromiso social, reiterando el lema de la universidad que dice: "esta universidad corresponde a todos los mexicanos», así mismo se pronunció a favor de la de la pluralidad ideología como signo de fortaleza de la institución. (DELGADO, Op. Cit.)

De igual forma su antecesor Juan Ramón de la fuente mencionaba que: habría que tener cuidado al avalar sin reflexión la tesis de subordinar la educación a las necesidades de los mercados, dado que la educación requería su espacio, su autonomía y su independencia, como parte del proceso formativo, ya que no debería olvidarse que el fin último y primero de la educación era convertirla en ese gran instrumento de permeabilidad social y de capilaridad social, pues si se perdía este elemento esencial estaríamos desnaturalizando la educación en sí misma. (DE LA FUENTE, 2005: p. 7)

Por su parte Gilberto Guevara Niebla, pedagogo y Ex subsecretario de Educación Básica mencionó que competitividad, democracia y justicia social son los tres grandes objetivos que deben tener en conjunto universidades públicas con los gobiernos, puesto que la esencia de ellas radica en la búsqueda soluciones para los grandes problemas nacionales que enfrenta el país.

Alude también a Justo Sierra por ser la persona que comprendió realmente que las universidades deberían tener en su misión una función social y sostiene que la universidad tiene que replantear sus objetivos para conocer hacia donde se dirige, qué quiere lograr; toda vez que como se ha mencionado, actualmente existen sobre la mesa tres grandes problemas que habrá que superar, como son: la competitividad, la

${ }^{3}$ Discurso pronunciado en la inauguración de la Universidad Nacional de México en 
democracia y la justicia social. Problemas que en su opinión debemos atacarlos directamente. (MENDOZA, 2007. p. 1-2)

En consecuencia y bajo el marco de la globalización y el neoliberalismo, podemos sostener que existe una gran concentración de riqueza y por consecuencia una extrema pobreza y desempleo pues el neoliberalismo con sus prácticas mercantiles y autoritarias ha favorecido el monopolio de las empresas trasnacionales, y si bien contamos con una rectoría económica lo cual obedece a la tradición mexicana de atribuir al estado la responsabilidad de organizar el desarrollo nacional conforme a lo dispuesto por los Artículos 25, 27, 28, 123 y 131 Constitucionales entre otros y de impulsar el desarrollo nacional como forma indispensable para integrar a la nación dentro de sus valores económicos y sociales, lo cierto es que el Estado al abandonar su papel de rector de la economía, ha reducido su planta de trabajadores, incrementándose el número de desempleados con las grandes consecuencias que esto ha traído consigo como se ha mencionado.

Por otra parte podemos observar que la historia registra que cuando los pueblos se ven amenazados por algún fenómeno social, económico, etc. nace la solidaridad entre ellos y el apoyo mutuo, destacándose el espíritu de colaboración y no sólo en periodos de catástrofes sino como fuente de apoyo de la especie humana, de consolidación y reconstrucción del tejido social.

En efecto, en los países pobres la autogestión y la auto determinación económica son totalmente compatibles con la democracia, razón por la que empiezan a reconsiderarse y a revalorarse las empresas familiares y asociativas, preecoperativas, cooperativas, el auto empleo etcétera, a través de una dimensión social y política, como un proceso de toma de conciencia de los actores sociales y como un proceso educativo que permite el surgimiento de una entidad colectiva y la capacidad de organización.

La autogestión y el cooperativismo son formas de organización validadas a lo largo de la historia que han ofrecido soluciones a los grandes problemas de los grupos humanos (económicas, de autovaloración, reencuentro como sujetos sociales y en suma el aprovechamiento de la iniciativa individual y social, bajo el apoyo mutuo en un clima de paz.

Por tanto si queremos la emergencia de una sociedad mas justa, culturalmente renovada, es necesario invertir la lógica del sistema entre los fuertes y los poderosos que sólo utilizan la tecnología avanzada para su beneficio, esto es: optar por un modelo de economía que sea social y solidaria contando que tal vez que en ocasiones convendrá desechar la sofisticación técnica y utilizar tecnologías apropiadas, sencillas y a escala humana que primen la proyección personal del trabajo a través de ellas y 
favorezcan la integración del grupo que las utiliza, pues el constitucionalismo y democracia son inseparables, ya que a partir del concepto de soberanía popular, el pueblo es soberano y de él emanan los poderes del Estado y en especial el poder constituyente como poder extraordinario para constituirse del modo que mejor le convenga. (COLOMER, 2007: 29)

Por otra parte el Constitucionalismo Social adoptado por nuestra constitución a través de diversos artículos, entre ellos el artículo 25 Constitucional que habla sobre la rectoría económica, pueden muy bien adaptarse a este modelo social y solidario toda vez que en el se reconoce al sector social de la economía sin distinción alguna .

Ahora bien, los estudiantes que son la razón de ser de la Universidad deben asumir la responsabilidad de formarse bajo una educación que contribuya al desarrollo cultural, profesional y personal, basado en una relación responsable con la sociedad.

Asimismo, la cooperación y el apoyo mutuo deben ser la base de las normas que los guíen, además que los propósitos institucionales de la universidad deberán ser el desarrollo de la investigación tecnológica y humanista, atendiendo a los retos científicos que la realidad exija.

De tal suerte que la producción cultural y el avance tecnológico extiendan sus beneficios a la sociedad mediante la cooperación académica y se defienda el patrimonio cultural mexicano, atendiendo el problema de la desigualdad social.

La cooperación académica deberá establecer relaciones con diversos grupos sociales mediante el desarrollo de proyectos de investigación y servicios profesionales con fines aplicados, con el objeto de extender sus beneficios.

La universidad pública debe estar vinculada y comprometida con la comunidad como una institución de servicio, tanto en el aspecto territorial de los pobladores como en el entorno de sus planteles así como con el apoyo de programas que incuben empresas sociales, que sean económicas, ecológicas y socialmente sustentables, ya que de esa manera la forma de pensar y organizar será diferente. (Universidad Autónoma de la Ciudad de México, p. 1-15)

De hecho en nuestros días el proyecto autogestionario y cooperativo parece recobrar nuevo vigor, presentándose como una alternativa válida en el terreno de la producción académica que comienza a extenderse como por ejemplo en la Universidad Autónoma de Chapingo, Estado de México, la Universidad de Querétaro, La Universidad de San Luís Potosí, la Universidad Nacional Autónoma de México, y la Universidad Autónoma de la Ciudad de México, entre otras más.

Se retoman así la autogestión obrera, la autogestión social, la autogestión política, la autogestión pedagógica, intentando con ello contra- 
venir la inercia de los espacios privados y particulares que sólo priorizan el beneficio personal y erradican la posibilidad de la cooperación y la autogestión a favor del beneficio colectivo.

Como puede observarse lo más importante es la educación, ya que es un factor esencial en la conformación de una sociedad libre, justa y democrática. Esta educación con visión crítica permitirá al educando autogestionarse social y personalmente, desarrollando capacidades en pos de la dirección humana, permeando el espacio académico con el entorno social y humano. (Idem).

Lo anterior resulta sumamente trascendental, pues como él citado escritor Antonio Colomer se pregunta ies posible que puedan ser titulares de soberanía por igual ciudadanos en situaciones de radical desigualdad y hasta excluidos y discriminados algunos de ellos?, ¿son estos conceptos tan sólo un mito político y por tanto una ficción jurídica? ó bien ¿si a pesar de todas las dificultades es un orden por construir, vertebrado por los valores de justicia, solidaridad, libertad e igualdad? A lo cual él mismo responde: todas estas situaciones plantean la dificultad de una democracia política sin democracia económica y también la necesidad de unas políticas solidarias que faciliten un equilibrio interpersonal, impulsando los medios para facilitar la igualdad y la libertad, siendo la solidaridad el fundamento de la constitucionalidad para alcanzar la igualdad de oportunidades, elemento indispensable para la paz social. (COLOMER, 2007: 31)

Por su parte Víctor Flores Olea, menciona:

«Frente a la disyuntiva entre planificación y mercado debemos enfatizar que la única forma para el desarrollo de las libertades individuales y con ello las de toda la sociedad, radica en la autoorganización y autogestión necesariamente comunitaria de los individuos que la conforman, de tal manera que se anule la preeminencia tanto del Estado como del mercado y que prevalezca universalmente el principio de la solidaridad. La experiencia Histórica muestra que el mercado va liquidando la posibilidad de satisfacer adecuadamente las necesidades colectivas e individuales, mientras que la concentración del poder del Estado liquida las libertades del individuo y de la sociedad» (FLORES, 2000: 293)

El citado Antonio Colomer, menciona: «un clamor universal se escucha en el mundo, por mas que se le quiere ahogar, la exigencia de una sociedad diferente, que reemplace la avidez, la agresión, la competitividad, la obsesión consumista; un mundo en el que podamos auto organizarnos y decidir por nosotros mismos; en donde la visión del otro como competidor u objeto de lucro se sustituya por el de compañero 
con el que establezcamos relaciones solidarias en un esfuerzo común» (COLOMER, 2002: 88)

En efecto, a pesar de la gran diversidad de alternativas existentes, el modelo de economía solidaria es hoy una realidad, ha enfrentado y seguirá enfrentando obstáculos para su instrumentación y desarrollo pero a la vez contiene dinamismos propios y concretizados en todo el mundo, que la hace confiable como camino seguro para la realización del hombre en su entorno productivo.

Ya sea que la economía solidaria se materialice en empresas cooperativas de gran envergadura, o en formas incipientes de participación ó de asociación, es sin duda un modelo que desafía concretamente a las formas individualistas y capitalistas de producción y distribución de bienes y servicios, dado su humanismo intrínseco y su carácter solidario.

Por otro lado es la forma en la cual el hombre se asocia con los demás hombres para producir los bienes necesarios, que permiten crear y controlar solidariamente las acciones realizadas. De hecho puede decirse que la solidaridad, no ha tenido tanta expresión en el plano objetivo como el cooperativismo.

La economía solidaria se relaciona con procesos de paz en aquellas regiones apartadas en las que se busca la inserción de los grupos en conflicto hacia un desarrollo y modernización económica pero con Justicia Social, ya que sólo de esta forma se construye una respuesta adecuada como lo es que: «...el énfasis de la política económica será la ampliación del mercado interno, la autosuficiencia alimentaría y el estimulo permanente de la producción, la pequeña y gran industria privada, a la autogestión a la microempresa y a la economía solidaria» (Economía Solidaria, 2003: 3)

La economía solidaria se define como: «...aquel conjunto de organizaciones que fundamentan su racionalidad económica y sus lógicas operaciones en la autogestión y la participación democrática de las comunidades productivas y sociales en las cuales se privilegian los objetivos y las expectativas de la comunidad y el trabajo como factores organizadores de la economía empresarial.» (CADENA, 2005: 26)

La economía solidaria se proyecta como una constructora del tejido social, capaz de regenerar las relaciones sociales hacia una economía más justa y pluralista, en donde coexistan; Estado, iniciativa privada y trabajo solidario, representando la diferencia, la autoridad y necesidades de los demás.

Se plantea también como un mecanismo del desarrollo alternativo, capaz de construir nuevas propuestas al quehacer económico y social en el campo de la autogestión democrática. De hecho la economía Social y Solidaria nace como una reacción a la exclusión social ó econó- 
mica de todos los beneficios básicos para la vida, por eso esta reacción puede considerarse ante todo como una actitud defensiva.

Dicha reacción no surge en forma individual sino que se da en forma colectiva, puesto que la economía social es siempre colectiva, es la forma en que el hombre se agrupa con los demás hombres para integrarse al esquema económico del que se siente excluido, reaccionando con los «otros», de forma igualitaria. Así el proyecto que llegue a construir incluye una responsabilidad compartida al igual que los beneficios que se obtengan, por eso a estas organizaciones se les llama también «sociedad de personas».

Por tanto puede afirmarse que es en este entorno en donde aparece la realización de la «utopía» al hablar de solidaridad, que se concreta necesariamente en una realidad compartida y en un esfuerzo común, ya sea en la construcción de una vivienda, en la construcción de una pequeña empresa etc. Siempre y cuando dicha "utopía» mida sus posibilidades y su viabilidad toda vez que esto denota una realidad económica distinta, esto es: denota una alternativa económica. (CASTRO, 2002: 37)

El modelo de economía social reacciona para neutralizar lo que siente como amenaza o exclusión, creando riqueza y compitiendo con el mercado pero de una manera alternativa. Su base económica son los ahorros de las personas generalmente hecho a base de esfuerzos, lo cual exige mayor transparencia y eficacia.

Pero el ingrediente que da mayor cohesión es la solidaridad, siendo tan fuerte este concepto que bien podría afirmarse es el motor de la economía social para la creación de empresas colectivas cuando estas sean creadas para el beneficio de todos sus integrantes, de forma igualitaria repercutiendo en el entorno social en forma de generación de empleo, en consecuencia hace falta tan sólo convencer a nuestros gobiernos de apoyar el desarrollo de esta economía social que parte de la base, «desde abajo» a través de políticas públicas, de la misma forma que brindan su apoyo al desarrollo de las empresas capitalistas y en general a la economía de mercado. Es necesario por tanto que los poderes públicos pongan en marcha políticas incluyentes para facilitar el desarrollo de todos los sectores sociales. (4)

En México como en otros países existen diversos grupos en los que participan activistas sociales, académicos, líderes, funcionarios de gobierno, en aras de generar acciones a través de espacios de reflexión y discusión colectiva con el propósito de poder consensuar un marco conceptual acerca de este modelo de economía alternativa, como: Pablo González Casanova, José Luís Calva, Julio Boltuinik, Félix Cadena Barquin, entre otros más, y en América Latina esta acción se ve coor- 
dinada por José Luís Coraggio (de Argentina), Francisco Gutiérrez (de Costa Rica), Luis Razeto (de Chile), Euclides Mance (Brasil), entre otros más. Participan también en torno a la disensión de la economía solidaria Francia y España. (CADENA, 2005: 13)

La economía solidaria se proyecta como una constructora del tejido social, capaz de regenerar las relaciones sociales hacia una economía más justa y pluralista, en donde coexistan; Estado, iniciativa privada y trabajo solidario, representando la diferencia, la autoridad y necesidades de los demás.

Se plantea también como un mecanismo del desarrollo alternativo, capaz de construir nuevas propuestas al quehacer económico y social en el campo de la autogestión democrática.

En México como en otros países latinoamericanos, la economía de mercado de tipo neoliberal fue un proceso que inició en la década de los años 80', sin embargo los resultado de tipo catastrófico están a la vista, los cuales han sido analizados ampliamente por destacados intelectuales, académicos, líderes sociales e incluso por grandes funcionarios del Banco Mundial y del Fondo Monetario Internacional, quienes han pugnado por la construcción de una economía diferente, de tipo incluyente.

La manera como puede adoptar la sociedad civil ese cambio, cubre muchas facetas, todo depende de la actividad que se quiera desarrollar y una de esas facetas es a través del cooperativismo toda vez que contiene valores y principios universales.

En efecto, el cooperativismo se inscribe en el marco de la economía social y solidaria, igual que un gran número de micro, pequeñas y medianas empresas y todas estas formas de producción constituyen agentes de cambio, sin embargo la cooperativa es sin duda uno de los punteros del proceso de producción de la economía solidaria.

Entre sus principales características destacan:

- Su desarrollo basado en principios universalmente aceptados

- Pertenece a un movimiento de alcance internacional

- Que a pesar de sus altibajos en su desarrollo existen grandes ejemplos exitosos en lo económico y en lo social en 100 países del mundo y en la mayoría de los sectores de actividad económica

- El capital humano que han logrado en sus cuadros dirigentes y socios de base, es el mejor patrimonio de una organización social.

- Cuenta con leyes que rigen su operación en la mayoría de los países 
- Contiene valores del trabajo colectivo para un fin común como: la solidaridad, la cooperación y la ayuda mutua, estableciendo condiciones adecuadas para el desarrollo humano sustentable (DOMÍNGUEZ, 2005: p. 176-179)

En base a lo anterior podemos afirmar que una buena política cooperativa puede contribuir como un actor más en nuestro país contribuyendo al desarrollo económico, social y cultural del conjunto, siempre y cuando esa política valorice los elementos que definen al cooperativismo.

Los elementos que definen la «identidad cooperativa» en los principios y valores que ofrecen los rasgos de su identidad y que son recogidos en la «Declaración de Identidad Cooperativa» de la Alianza Cooperativa Internacional, (A. C. I.), en Manchester Inglaterra en 1995 son:

- Asociación voluntaria abierta

- Control democrático de los miembros

- Participación económica

- Autonomía e independencia

- Educación, entrenamiento e información

- Cooperación entre los miembros

- Compromiso con la comunidad.

Por tanto consideramos que el modelo cooperativo puede tener un real significado en la batalla contra la pobreza y el desempleo, como ya lo tuvo en el pasado, ya que refuerza las relaciones solidarias dentro de una comunidad y la confianza dentro de la propia empresa, gracias a las relaciones de trabajo, las cuales no están fundadas sobre la explotación, sino en avanzar en el camino novedoso de la democratización, de avanzar a la economía y la sociedad implicará la transformación de mercado y del estado, la construcción de una nueva ética y de un desarrollo social y solidario que nos llevara seguramente hacia una nueva forma de civilización.

Y es a las universidades públicas del país a quienes toca esta enorme responsabilidad de formar individuos que cuenten con valores que les permitan pensar en sus pares, vecinos, conciudadanos etc., basando sus acciones y principios en valores humanos, lealtad, honestidad, respeto, que les conviertan en trabajadores de la paz social con gran integridad personal.

Que sepan desarrollar habilidades que les permitan resolver conflictos y desempeñarse como líderes, con una comunicación abierta y clara, que sean negociadores equitativos con claros objetivos y con capacidad para establecer puentes humanos cuya perspectiva esté orientada hacia la equidad. 
Dentro de los programas que se ofrecen en algunas de las universidades públicas del país como la Universidad Autónoma de la Ciudad de México, se citan las ventajas de este modelo, señalando que es necesario conocer:

- El beneficio de la cooperación y el apoyo mutuo

- El proceso autogestivo con sustento social, económico y ecológico

- Las bases filosóficas e históricas del cooperativismo

- Los tipos de organizaciones y modelos de cooperación en el contexto mundial

- Los diferentes modelos de autogestión

- Los fenómenos de la formación de grupos

- Los procesos sociales favorables para una convivencia democrática

- Las redes de economía solidaria

- La gestión de procesos formales para la constitución de empresas cooperativas

— Las habilidades de administración y operación de organizaciones

- Los fenómenos contemporáneos de autonomía indígena

- Los procesos de administración comunitaria en relación con la administración pública

- Los procesos de autogestión y promoción en movimientos sociales y

- Los procesos de autogestión académica y de autonomía universitaria

Para que sean capaces de realizar las siguientes actividades:

- Diagnosticar los grados de autogestión, cogestión y heterogestión para plantear mejoras en la efectividad y sustentabilidad de las relaciones sociales.

- Evaluar los fenómenos que se presenten en la formación de grupos y sepan proponer dinámicas de grupos para su mejor integración y funcionamiento

- Investigar las funciones sociales emergentes que favorezcan principalmente a las redes de economía solidaria y

- Organizar y gestionar los procesos formales de constitución y registro, administración y operación de empresas en su contexto comunitario y social específico (indígena, académico, urbano, popular etc) (Universidad Autónoma de la Ciudad de México 1-15)

Carlos Montemayor menciona que estamos viviendo en una época que se caracteriza por el desplazamiento de las categorías clásicas y 
un ascenso de una nueva forma de composición política y económica del mundo, en la que los países se definen con nuevos valores económicos y la población se somete a un nuevo concepto de la naturaleza del hombre y de los derechos humanos, que en materia económica podríamos llamar "un nuevo colonialismo».y el mismo se pregunta: ¿debemos permitir que el concepto de universidad como una comunidad académica desaparezca? ¿la educación superior debe ser un fragmento del libre mercado que sólo capacite recursos humanos para que puedan vivir en la globalización? ó debemos luchar por el fortalecimiento de la educación misma como mejor recurso para el fortalecimiento del país entero? (MONTEMAYOR, ibidem)

Como puede observarse, no conviene que la educación superior en México sea un producto del mercado, ni debemos aceptar la idea de que los beneficios para la población estudiantil de las universidades públicas dependerán del aumento del mercado, toda vez que ello dependerá de una buena política por parte del Estado que siga considerando a la educación superior como una prioridad nacional, ya que las universidades son quienes afrontan una gran responsabilidad social en un proceso de bienestar y de desarrollo . En consecuencia no debe reducirse el presupuesto destinado a ellas.

\section{Autogestión y cooperativismo}

A lo largo de la historia han sido muchas las organizaciones de hombres que se han unido con fines comunes bajo los principios del cooperativismo; muchas han logrado funcionar con éxito, otras se han quedado en un simple intento; lo cierto que el contenido de éste derecho bien aplicado obtiene siempre resultados exitosos.

Trueba Urbina da una definición sobre derecho cooperativo:

«El derecho cooperativo es el conjunto de principios y reglas, que fijan los deberes y garantizan las facultades de la organización cooperativa en su régimen interno y sus relaciones con el Estado y la comunidad para realizar un fin social de justicia distributiva y democracia económica...» (TRUEBA, 1978:450)

Existe también otra definición surgida a la luz del artículo 123, de sus leyes reglamentarias y de la Ley General de Sociedades Cooperativas que menciona; "El derecho cooperativo es el conjunto de principios, instituciones y normas protectoras de los trabajadores, destinadas a conservar y superar las reivindicaciones proletarias en el trabajo 
en común o colectivo y en el goce de los beneficios de la previsión social...» (ídem)

Francisco González Díaz Lombardo dice que el derecho cooperativo es una rama del derecho social que tiene por objeto ordenar a individuos de la clase trabajadora que se organizan aportando su trabajo personal (cooperativas de productores) o utilizan o se aprovisionan de los servicios que de la misma se servirán (cooperativas de consumidores). Funcionan sobre los principios de igualdad en derechos y obligaciones, su sociedad normalmente no persigue fines de lucro y procuran el mejoramiento social y económico de sus asociados mediante la acción conjunta de éstos en una obra colectiva. (GONZÁLEZ, 1978: p. 71)

Luego entonces por el hecho de contar con principios propios, metódicamente ordenados el derecho cooperativo es una ciencia, además al ser un conjunto de reglas que fijan deberes y garantizan facultades, participa de las acepciones de sujeto y objeto que caracterizan a la palabra derecho en términos generales.

\section{Características del Derecho Cooperativo}

El derecho cooperativo tiene las siguientes características:

- Es un derecho de clase como comenta Antonio Salinas Puente por que:

«En tanto que el derecho mercantil es el derecho de la economía capitalista, el derecho cooperativo se afirma con el derecho de los trabajadores en su calidad de miembros de una clase social.

- Es un derecho de organización:

Por que el derecho mercantil moderno basa su estructura en el concepto de empresa y el derecho cooperativo lo funda en el principio de organización dentro de la cual se comprenden sociedades, federaciones, confederación nacional e instituciones auxiliares.

- Es un derecho autónomo:

Pues el derecho cooperativo tiene vida propia; se caracteriza por la ausencia de Lucro y de intermediación, tiene una finalidad basada en el beneficio social, cuenta con Principios jurídicos y con instituciones claramente diferenciados en relación a las demás ramas del derecho... (SALINAS, 54:16-17) 
Con los caracteres anteriormente señalados podemos observar que el derecho cooperativo trasciende las fronteras nacionales y nos demuestra que el mismo, representa en su conjunto una esperanza de paz y bienestar para el futuro.

\section{Concepto de Movimiento Cooperativo}

El propósito de toda comunidad es lograr un bienestar para todos sus integrantes; dado que es común, que en ocasiones se obtenga un beneficio mayor en detrimento de otros, lo cual como consecuencia lógica ocasiona una pugna entre diversos grupos.

La lucha de clases se da como consecuencia de las desigualdades entre grupos, solo puede evitarse mediante una mejor distribución de la riqueza. La empresa cooperativa coadyuva a que se combata todo acto especulativo y monopolístico en defensa de núcleos económicamente débiles.

A esta actitud de lucha del hombre por combatir las injusticias cometidas en su contra; se denomina «Movimiento Cooperativo».

Los tejedores de Rochdale se organizaron para manifestarse en contra de la explotación industrial que se encontraba en auge; al observar los pioneros que con la huelga no se lograba nada, éstos decidieron formar una sociedad cooperativa, que sería el instrumento para Luchar en contra de los intermediarios; en consecuencia a la actividad que realizaron éstos pioneros se denominó: «movimiento cooperativo».

No debe confundirse el término movimiento cooperativo con el término organización cooperativa, toda vez, que la organización cooperativa es la estructura jurídica, formal y automática del cooperativismo y el movimiento debe entenderse como la función dinámica de éste sistema.

Salinas Puente menciona:

«El movimiento cooperativo es la inconformidad en contra de la injusticia económica, la rebeldía en contra de las instituciones de explotación industrial y comercial; la lucha altruista que se desarrolla momento a momento en un mundo saturado de egoísmo.

También el movimiento cooperativo es una actitud constructiva; un proceso de superación constante, intervención ante los órganos del Estado para consagrar, en la legislación, los nuevos principios económicos, sociales y jurídicos que constituyen su objeto..» (Idem)

En base a lo anterior puede decirse que el movimiento cooperativo es una fuente creadora de derecho; producto de las luchas realizadas 
con la finalidad de lograr la defensa de los intereses de los económicamente débiles.

\section{Cooperativismo}

Salinas Puente citando a Charles Gide menciona que el cooperativismo es: "todo un programa de renovación social; representa un esfuerzo colectivo de la sociedad humana, encaminado a cambiar el actual estado económico del mundo y a terminar con la explotación que sufre el hombre en sus condiciones, de consumidor y productor...» (Idem)

La concepción que tiene éste autor acerca del cooperativismo es que mediante una renovación social, el hombre transforma la estructura económica existente, de tal manera de que sea el capital quien esté al servicio del hombre y no el hombre al servicio del capital; de ésta manera logra obtener el individuo lo que merece; según el esfuerzo que éste haya aportado para producir riqueza.

El programa propuesto por el profesor Gide tiene como propósitos principales; destruir las injusticias del capitalismo, evitar cualquier forma que implique un enriquecimiento individual en detrimento de otros; evitar que se obtengan provechos individuales con el producto de un esfuerzo colectivo.

El cooperativismo es el modo como se transforma y se distribuye la riqueza; de tal manera que ésta beneficie a quienes contribuyen con su esfuerzo personal para su realización.

El cooperativismo pretende también acercar a los hombres; y con esto crear lazos de unión entre ellos, formar un espíritu de solidaridad basado en la igualdad pretende también, que no exista distinción de credo; división entre ricos y pobres; además, el cooperativismo pretende eliminar la existencia de explotadores y explotados.

Como puede observarse el cooperativismo como tal encierra en si mismo propósitos económicos, morales, sociales y educativos toda vez que agrupa a los hombres en sociedades; su finalidad no es el lucro, sino satisfacer las necesidades económicas de sus conciudadanos.

Distribuye las riquezas y el capital, entre los mismos hombres que lo producen. Cada individuo, dentro de la economía cooperativista, es propietario de una parte del capital invertido en la empresa común cooperativa mediante su certificado de aportación. No hay explotados ni explotadores, ni consecuentemente diferencia de clases.

Permite que las utilidades del nuevo capital sean verdadera y justamente distribuidas y auténticas renovadoras de la riqueza agotada. 
Devuelve al hombre su perdida categoría y dignidad al considerarlo no por su dinero sino por su persona, porque en las cooperativas votan los hombres y no las acciones, no los capitales.

Antonio Colomer menciona: "Somos hijos de nuestra cultura, de nuestro arraigo, de nuestra vinculación a ese entorno entrañable en el que hemos crecido. No existe es verdad el hombre abstracto, sin raíces; pero al mismo tiempo, sin negar lo constitutivo diferencial de los distintos grupos humanos, de sus asideros culturales, también reconocemos el carácter profundamente universal de la identidad humana, los sonrisas, las lagrimas, el sentimiento de injusticia por el daño gratuito, el respeto al compromiso libremente adquirido, la indignación ante el manejo del hombre como un puro instrumento de otro hombre, son significados universales en los que todos podemos coincidir.» (COLOMER 2002, p. 48)

Con éste sistema de producción económica como se le ha llamado al cooperativismo; se pretende realizar el bien común, terminar con cualquier tipo de injusticia inhumana; pues el verdadero establecimiento de una organización cooperativa implica necesariamente mejorar las condiciones de vida de los organizados.

Antonio Salinas Puente define al cooperativismo «como un sistema de organización jurídica de la clase trabajadora que tiene por objeto realizar en común un fin social de justicia distributiva y democracia económica...» (SALINAS, 1954: 52)

Para Rosendo Rojas Coria «El cooperativismo es un movimiento revolucionario pero pacífico cuya estructura se adapta a todos los pueblos de vida civilizada, es respetuoso con todas las constituciones políticas y con las creencias religiosas y se desenvuelve lenta, pero firmemente por medio de la razón, la verdad y sus resultados benéficos...»(ROJAS, 1984:132)

Son diferentes las conceptualizaciones que existen sobre cooperativismo; sin embargo, todas coinciden en que mediante éste; las personas; en sociedad y libremente unidas sobre las bases de igualdad en derechos y obligaciones; enfrentan dificultades económicas, y se esfuerzan por resolverlas; teniendo siempre en la mira la finalidad de obtener un provecho general; mediante la colaboración moral y material de todos.

\section{Concepto de Cooperativista}

En virtud de que el cooperativismo en nuestro país ha estado durante mucho tiempo vinculado con la idea de cooperación entre tra- 
bajadores y productores tanto obreros como campesinos, que tienden a unirse para desarrollar actividades de beneficio común aportando su trabajo y capital para constituir una organización de colaboración y de control de actividades productivas o de distribución y comercialización de bienes y servicios, es por lo que el término cooperativista tiene una connotación tan amplia que se puede utilizar no solo para identificar a los trabajadores asalariados; sino también, a los servidores del estado, ejidatarios y cualquier grupo de individuos organizados con la finalidad de establecer una cooperativa.

Éstos sectores han comprendido que es necesario ampliar el sector social y otorgarle otro sentido a la cooperación dentro del marco de las transformaciones que requiere el país.

\section{Etimología del Concepto Cooperativista}

Salinas Puente menciona que resulta redundante la expresión «trabajador cooperativista» si se tiene en cuenta la etimología del vocablo. Pues la palabra cooperativista se deriva del latín: cum (junto) y operare (trabajar). Por su origen, el cooperativista es, necesariamente, un trabajador, que por tanto cooperativista «es toda persona física, perteneciente a la clase trabajadora, que subsiste con el producto de su esfuerzo individual, material, intelectual o de ambos géneros, aportado a la realización de una obra conjunta de democracia económica y de justicia distributiva...» (SALINAS: op. cit)

Dicho autor entiende por clase trabajadora, al conjunto de obreros, campesinos, servidores del estado, artesanos, profesionales y en general a la población económicamente débil, que tiene una ideología definida y que pretende por medios colectivos luchar por obtener una liberación; en éste caso de la explotación a la cual se encuentra sujeto en su calidad de trabajador. No obstante a partir de las reformas realizadas a la Ley General de Sociedades cooperativas en Mèxico con fecha 3 de agosto de 1994 puede decirse que: el cooperativista no necesariamente tiene que ser una persona física perteneciente a la clase trabajadora; sino que ésta Ley da margen para que el cooperativista sea cualquier persona física que tenga intereses comunes, y que bajo los principios de solidaridad, esfuerzo propio y ayuda mutua, trabaje con el propósito de satisfacer necesidades individuales y colectivas, a través de la realización de actividades económicas de producción, distribución y consumo de bienes, y servicios sin limitar a que la persona física que realice lo anterior pertenezca a la clase trabajadora. 


\section{Cooperativa}

Rosembuj Tulio menciona que: "La cooperativa es una entidad basada en la autonomía de voluntad de las personas que la integran para satisfacer sus necesidades económicas así como las de naturaleza cultural y social, mediante el esfuerzo propio y la ayuda mutua...»

Atendiendo a su etimología la palabra cooperativa viene de la voz latina cooperari de com; y operari; trabajar dando como significado, obrar juntamente con otro u otros para un mismo fin.

El mencionado autor continua diciendo:

«La cooperativa es una organización jurídica con objeto de satisfacer una necesidad social encaminada a transformar a la sociedad por medio del sistema cooperativo, a través de una asociación voluntaria de un número de personas que tienen fines económicos comunes para la explotación de una empresa colectiva, organizada con base en los principios de igualdad de derechos y obligaciones...» (ROSEMBUJ, 1964:9)

Como se observa la razón de ser de una cooperativa; estriba en la necesidad de ayuda mutua para superar limites en el desarrollo de una actividad deseada. La cooperativa es pues el medio que permite al hombre lograr resultados mas allá de los que pudiera alcanzar en forma aislada.

Lo que se pretende con el establecimiento de una sociedad cooperativa; es formar una sociedad de personas dispuestas a reunir voluntariamente su energía a fin de realizar una obra benéfica para los integrantes de dicha sociedad.

La cooperativa se caracteriza siempre por la finalidad de servicio a los miembros o al entorno, por los procesos de decisión democrática, por la primacía de las personas y del trabajo sobre el capital en el reparto de los beneficios. Es un grupo de personas pequeño o grande, con el compromiso de asociar su acción sobre las bases de democracia y autoayuda en orden a asegurar un servicio o acuerdo económico que es a la vez, socialmente deseable y beneficioso para todos los que participan. (HERNÁNDEZ, 2001: p. 27)

El punto de partida para el buen funcionamiento de una cooperativa es la autoorganización

Las cooperativas conservan el espíritu de autoayuda como equivalente a la idea de lucro en la empresa mercantil o al interés público en 
empresa estatal. En la cooperativa la autoayuda es la prolongación voluntaria y colectiva del ánimo individual, la reunión de hombres libres para completarse en un resultado común.

En conclusión puede decirse que la cooperativa es un medio de participación, un instrumento por medio del cual se les da el derecho de participar a los ciudadanos en la vida económica, social y cultural del país.

\section{Concepto de Trabajador en el Derecho Cooperativo}

En atención a que la Ley General de Sociedades Cooperativas de 1938 consideraba como condición para la existencia de éstas; el hecho de estar integradas por individuos de la clase trabajadora; es pertinente mencionar el concepto de trabajador:

La Ley Federal del Trabajo en el artículo 8 señala que trabajador es la persona física que presta a otra, física o moral, un trabajo personal subordinado.

Esta disposición lleva a la idea de que trabajo es toda actividad humana, intelectual o material independientemente del grado de preparación técnica que se requiera para cada profesión u oficio.

Por su parte el derecho cooperativo (art. 2 de la L.G.S.C de 1938), da un concepto de trabajador: ...todo aquel individuo que pertenece a la P.E.A (población económicamente activa) y vive preponderantemente de la venta de su fuerza de trabajo.

Combinando los anteriores conceptos puede decirse que el trabajador es la persona física que presta a otra, (física o moral) un trabajo personal subordinado y vive preponderantemente de la venta de su fuerza de trabajo.

Si se adecua lo señalado en el artículo 8 de la Ley Federal del Trabajo a lo establecido en el artículo 2 de la Ley General de Sociedades Cooperativas, se observa que la organización social se integra por personas físicas con base en intereses comunes; las personas físicas son consideradas como trabajadores, si se toma en cuenta que el articulo señalado primeramente nos dice que el trabajador es una persona física.

Sociedad o Empresa Cooperativa

En relación a éste concepto es necesario aclarar que la forma «indistinta» con que se emplea el término: empresa o sociedad coopera- 
tiva, se debe a que siempre se ha ubicado a la Ley General de Sociedades Cooperativas dentro de la Ley General de Sociedades Mercantiles, llegando a considerarse algunas veces como una sociedad mercantil de las que reconoce la ley, olvidándose de su naturaleza especial, situación que obedece a un análisis exhaustivo que realizamos en el Capítulo Quinto.

Por otra parte, la Alianza Cooperativa Internacional (ACI) en el año 1995 define por primera vez a las cooperativas reafirmando sus principios y sus valores que las caracterizan y también por primera vez utiliza el término de «empresa cooperativa».

Consecuentemente puede decirse que ambos términos son aceptables en el léxico jurídico.

Por su parte Rosendo Rojas Coria la define como la organización concreta del sistema cooperativo, que lleva en si el germen de un asalariado, socialmente encaminada a abolir el lucro y el régimen de asalariado, para substituirlos por la solidaridad y la ayuda mutua, sin suprimir la libertad individual...» (ROJAS, 1984: p. 615)

La Ley General de Sociedades Cooperativas vigente en nuestro país (1994) la considera como: «una forma de organización social integrado por personas físicas con base en intereses comunes y en los principios de solidaridad, esfuerzo propio y ayuda mutua, con el propósito de satisfacer necesidades individuales y colectivas, a través de la realización de actividades económicas de producción, distribución y consumo de bienes y servicios...»

Sin embargo la sociedad o empresa cooperativa va mas allá de ser una organización social, laboral o económica, nos estamos refiriendo a una asociación de personas que en un número variable se enfrenta a dificultades económicas, las cuales libremente unidas sobre la base de igualdad de sus derechos y obligaciones, se esfuerzan por resolver esas dificultades, administrando por su cuenta todo lo relacionado con dicha sociedad, con miras al provecho general, material y moral mediante la colaboración de todos.

\section{Doctrina Cooperativa}

Eduardo García Maynez menciona:

«Se da el nombre de doctrina a los estudios de carácter científico que los juristas realizan acerca del derecho, ya sea con el propósito puramente teórico de sistematización de sus preceptos ya con la finalidad de interpretar sus normas y señalar las reglas de su aplicación. 
Como la doctrina representa el resultado de una actividad especulativa de los particulares, sus conclusiones carecen de fuerza obligatoria, por grande que sea el prestigio de aquellos o profunda la influencia que sus ideas ejerzan sobre el autor de la ley o las autoridades encargados de aplicarla...» (GARCíA, 1951:72)

Los principios a los cuales debe sujetarse todo régimen cooperativo son los siguientes:

- Combatir el egoísmo para sustituirlo por una nueva conducta típica en donde se da la libertad y la unión social.

- Luchar porque no exista la idea de lucro y así mismo desaparecer el término de asalariado.

- Luchar porque existan leyes y se estatuya el movimiento cooperativo de acuerdo a su avance.

- Marchar pacífica y firmemente hasta lograr conquistar a la sociedad en general.

El movimiento cooperativo, ha pretendido no sólo introducir nuevos principios de organización económica sino una nueva ética social...

El Derecho Cooperativo procura la organización y protección de los integrantes de una sociedad productora o consumidora de bienes o servicios.

El objeto del derecho cooperativo es la unión libre de personas que aspiran satisfacer sus necesidades en forma directa e inmediata, a través de la ayuda mutua y de la unión, basándose en reglas libremente aceptadas.

El objeto del derecho cooperativo es procurar que los cooperativistas obtengan los bienes necesarios para su subsistencia con la mayor economía posible; tengan todos los servicios que necesiten y que obtengan grandes beneficios con su trabajo.

De hecho puede decirse que se contemplan tres objetivos fundamentales con los que el cooperativismo pretende superar las concepciones capitalistas y socialistas en relación al sistema económico y a sus efectos, ya que se promulga la libre asociación de individuos quienes tienen intereses comunes. Los objetivos son los siguientes:

a) Económicos. La tendencia es reducir precios de lo que se quiere adquirir, mejorando los productos que se elaboran y a mejor precio.

b) Sociales. Se procura la defensa del sector social o de la clase trabajadora para que exista una justicia social.

c) Educativos. Las cooperativas tienden a convertirse en centros donde se realizan actividades administrativas y financieras; 
donde se desarrollan técnicas de producción en forma masiva que no tienden a ser elitistas con los integrantes de la cooperativa... (ROJAS, 1984: p. 661)

El cooperativismo utiliza un instrumento, que es la empresa, aunque introduce unas diferencias muy importantes con otros tipos de empresa, especialmente con la Sociedad Anónima.

Principales diferencias entre una empresa capitalista y una empresa cooperativa.

\begin{tabular}{|l|l|}
\hline \multicolumn{1}{|c|}{ Empresa Capitalista } & \multicolumn{1}{c|}{ Empresa Cooperativa } \\
\hline El hombre busca la ganancia & $\begin{array}{l}\text { El hombre busca el servicio, además } \\
\text { del beneficio común }\end{array}$ \\
\hline $\begin{array}{l}\text { Con la ganancia se beneficia el } \\
\text { propietario del capital }\end{array}$ & $\begin{array}{l}\text { Con la ganancia se beneficia el } \\
\text { servicio }\end{array}$ \\
\hline $\begin{array}{l}\text { Principal objetivo: ensanchar los } \\
\text { márgenes hasta hacerlos lo más } \\
\text { provechosos posibles para el capital }\end{array}$ & $\begin{array}{l}\text { Operar con márgenes justos, a base } \\
\text { de precios lo más razonables que se } \\
\text { puedan. Ofrecer servicio en vez de } \\
\text { lucro }\end{array}$ \\
\hline $\begin{array}{l}\text { El beneficio logrado se distribuye } \\
\text { entre los accionistas }\end{array}$ & $\begin{array}{l}\text { El beneficio logrado (excedentes } \\
\text { disponibles) se devuelve a los socios } \\
\text { en proporción a sus actividades o } \\
\text { servicios }\end{array}$ \\
\hline El capital dirige; la persona, no & La persona dirige, el capital no \\
\hline La persona no tiene ni voz ni voto & La persona tiene voz y voto \\
\hline El número de socios es limitado & $\begin{array}{l}\text { El número de socios es ilimitado. } \\
\text { Pueden ser socios todas las personas } \\
\text { que lo deseen, según Estatutos }\end{array}$ \\
\hline $\begin{array}{l}\text { Los objetivos son independientes del } \\
\text { socio }\end{array}$ & $\begin{array}{l}\text { Los objetivos son dependientes de } \\
\text { las necesidades de los socios }\end{array}$ \\
\hline Administra no. reducido de personas & $\begin{array}{l}\text { Se gobierna con la participación de } \\
\text { todos los socios }\end{array}$ \\
\hline Se da la competencia & Se da la ayuda mutua \\
\hline
\end{tabular}

${ }^{4}$ Fuente: Juliá y Server, M.A.P.A. (1990).

http://www.infoagro.com/cooperativismo/asociacionismo_agrario2.asp

4 Discurso de la 3ra. Reunión de la Asociación Internacional de Universidades, México 1960. 
Como puede observarse ambas empresas difieren profundamente tanto en los valores como en los fines que persiguen, encontrando en ambas la sustancia social y económica pero enfocada hacia distintas direcciones.

\section{A manera de conclusión}

Como hemos visto México durante décadas México asignó a la educación el papel preponderante de ser una prioridad nacional, traducida en nuestra Carta Magna como el derecho a la educación (Art. $3^{\circ}$ Constitucional).Las normas que la regularon a lo largo de la historia tuvieron como característica el que siempre expresaron los anhelos y las necesidades del país, reflejándose de manera inequívoca en la historia de la educación nacional, y en cada etapa de la historia una estructura jurídica bien definida que correspondió a las ideas que sustentaron el periodo correspondiente.

Por su parte la universidad pública en México siempre fue un factor fundamental para el desarrollo del país, gran parte de lo que puedo hacerse dependió de la formación de los científicos, técnicos, administradores, médicos, etc. quienes fueron capaces de aprovechar los recursos e infraestructura que existía en el país en su intento por cambiar determinadas formas de organización social.

Desde este punto de vista puede asegurarse que la educación superior siempre jugó un papel muy importante en la vida institucional del país, pues de ella dependieron en gran medida sus alcances, y siempre estuvo orientada hacia la búsqueda de una sociedad más justa y de un desarrollo mas equitativo, pues en su evolución histórica encontramos que la educación superior desempeñó un papel importante en la construcción del México Posrevolucionario.

Sin embargo y no obstante los derechos sobre la educación en México, a partir de nuestra inclusión al Tratado del Libre Comercio, actualmente se observan los efectos negativos en nuestro país, pues existe un grave aumento del desempleo que provoca salarios cada vez más bajos, carencias de seguridad social, e inestabilidad laboral y de derechos sociales que con tanto esfuerzo se habían logrado establecer y aún cuando las economías se reactivan y los volúmenes de negocios aumentan, esto no se refleja ni en la cantidad ni en la calidad de los empleos generados y menos aún en la disminución de la pobreza, lo que ha traído como consecuencia: el desempleo, el comercio informal, el crimen organizado, la emigración hacia los Estados Unidos, el narcotráfico etc. etc. 
Las universidades por su parte pasan por una asfixia financiera que les obliga a replantear sus postulados y a hacer más eficientes sus recursos, ante la amenaza de desaparición de muchas de ellas.

Esta situación obliga a replantear sus valores y sus objetivos, sin olvidar que desde su inicio hace casi cien años la universidad pública siempre ha tenido un gran compromiso con la sociedad, y bajo este contexto el nuevo rector de la Universidad Nacional Autónoma de México Dr. José Narro Robles se ha pronunciado por elevar la calidad académica pero con compromiso social.

Las universidades del país coinciden con esta postura y coinciden también al afirmar que la situación financiera por la que actualmente atraviesan, es el resultado de un proceso en que el Estado está dejando de cumplir sus funciones constitucionales en aras del proyecto neoliberal

Por ello las universidades y los estudiantes que son la razón de ser de la Universidad deben asumir la responsabilidad de formarse bajo una educación que contribuya al desarrollo cultural, profesional y personal, basado en una relación responsable con la sociedad, asumiendo que la cooperación y el apoyo mutuo deben ser la base de las normas que los guíen, además que los propósitos institucionales de la universidad deberán ser el desarrollo de la investigación tecnológica y humanista, atendiendo a los retos científicos que la realidad exija.

De forma tal que la producción cultural y el avance tecnológico extiendan sus beneficios a la sociedad mediante la cooperación académica y se defienda el patrimonio cultural mexicano, atendiendo el problema de la desigualdad social.

La universidad pública deberá establecer relaciones con diversos grupos sociales mediante el desarrollo de proyectos de investigación y servicios profesionales con fines aplicados, con el objeto de extender sus beneficios.

La universidad pública debe estar vinculada y comprometida con la comunidad como una institución de servicio, tanto en el aspecto territorial de los pobladores como en el entorno de sus planteles así como con el apoyo de programas que incuben empresas sociales, que sean económicas, ecológicas y socialmente sustentables

No debemos permitir que el nuevo «colonialismo» dentro de su proceso globalizador desplace financieramente a las universidades, pues esta política de economía global impuesta en el mundo ha producido un desmesurado avance de pobreza y un proceso acelerado de concentración de riqueza, destruyendo las economías locales y abriendo las fronteras para las grandes inversiones, pero cerrandolas para los inmigrantes. 
El fortalecimiento de la educación misma basado en la solidaridad y el apoyo mutuo será el mejor recurso para el fortalecimiento del país, pues la universidad pública debe estar comprometida con la comunidad y los estudiantes deberán estar a la vanguardia cuidando que sus planes y programas de estudio no se transformen en programas de servicio para el mercado, sino que se transformen en planes que extiendan el beneficio de sus conocimientos a toda la sociedad en general a fin de alcanzar un sociedad justa libre y democrática.

\section{Bibliografía}

AdALID, Mario Edgar Comentarios al Artículo Tercero Constitucional. México editorial Porrúa y UNAM 2004

Atalli; Jaques. Desarrollo de la economía social y solidaria: necesidades y oportunidades. Foro Internacional de Economía Social y Solidaria (memoria) México. Secretaría de Economía, Comisión de Fomento Cooperativo de la LVII Legislatura Federal.2002

AvILËs Karina. Ocho rectores latinoamericanos condenan esa doctrina que «conduce a la agonía» México 2003: http:www.jornada.unam.mx

Cadena Barquín, Félix. De la economía popular a la economía de solidaridad. México, Editorial FOMIX, ECOSOL, Colegio de México. Se Puede.2005

CASTRO Sans, Marcos de. La economía social y solidaria Proyecto complementario e incluyente. .Foro Internacional de Economía social y Solidaria (memoria), México. Secretaría de Economía Fomento Cooperativo y Economía Social (FONAES) 2002

Colomer Viadel, Antonio. Autogestión democracia y cooperación para el desarrollo. Madrid, Acción Cultural Cristiana 2002

Colomer Viadel, Antonio. Comunidades y Ciudades, Constitución y solidaridad. Valencia España, Universidad Politécnica de Valencia. 2007

De La Fuente, Ramón. La Universidad. La inteligencia de los países. México. Revista: Foreign Affair en Español Instituto Tecnológico Autónomo de México (ITAM).Vol.5 No. 2. 2005

Delgado Moya ,Arturo. Función social de la universidad. México 2007: http:// WWW.el porvenir.com.mx/notas.asp?nota_id=175991

Dominguez, Juan Gerardo. Reticulaciones entre empresas auto sugestivas. El fin del dinero y restauración del crédito social. México, Editorial FOMIX, ECOSOL, Colegio de Tlaxcala, Se puede. 2005

Flores Olea, Víctor. Crítica de la globalidad. México. Fondo de Cultura Económica (FCE) 2000

ForRester, VIviane. Una extraña dictadura. México. Fondo de Cultura Económica. 2000

Garcïa Mynez, Eduardo. Introducción al Estuario del Derecho. 4. ${ }^{a}$ Edición México, Porrúa. 1951.

Gonzälez Díaz Lombardo, Francisco. El derecho social y la seguridad social integral. México 2. ${ }^{a}$. Edición. Universidad Nacional Autónoma. De México 1978 
Hernändez Perlines, Felipe. (Coordinador) La economía cooperativa como alternativa empresarial. Cuenca .Ediciones de la Universidad de Castilla Ña Mancha.2001.

JULIÄ y Server M.A.P.A. 1990: http://WWW.infoagro.com/cooperativismo/asociacionismo_agrario2.asp

Mendoza Lemus, Gustavo.- Resolver problemas del país, objetivo de las universidades. México. Junio 2008:

http://www.el porvenir.com.mx/notas.asp?nota_id=142587

Morales Sales, Samuel. La enseñanza de la administración pública en México. México. Universidad Autónoma del Estado de México (UAEM) 1981

Montemayor, Carlos. Universidad Pública y privatización del conocimiento. México dic.2006: http://www.jornada.unam.mx/2006/12/20index.phpectio $\mathrm{n}=$ sociedad\&article $=044 \mathrm{n} 1 \mathrm{soc}$

PuYANA; Alicia y José Romero. La economía mexicana después de dos decenios de reformas .México. Revista de Comercio Exterior No.10.Vol..57.2007.

Proceso Revista. México no.1622,2 dic.2007

Rojas Coria, Rosendo. Tratado de Cooperativismo Mexicano. México, Fondo de Cultura Económica (FCE) 1984

Rosembuj; Tulio. La empresa cooperativa. Perú.Biblioteca Central de Cooperativismo. Ediciones CEAC.1964.

Salinas Puente, Antonio. Derecho Cooperativo Mexicano.México, editorial Cooperativismo, 1954.

TRUEBA Urbina, Alberto. Derecho Social Mexicano, México, Porrúa.1978

- Economía solidaria en el proceso hacia la paz: posibilidad de una utopía, Coopnetal.org/aldia:Infcoopnetaldia

UniversidAd Autónoma de LA CIUDAD De MéXICo. Programa de autogestión cooperativa. Programa de estudios para el diplomado. Promoción en autogestión cooperativa. Marzo 2005: http:www.uacm.edu.mx/pac/diplomado.html 
